\title{
Review Paper: Living Plant-Mediated Synthesis of Nanoparticles
}

\author{
Saeed Taghizadeh$^{1}$, Seyedeh-Masoumeh Taghizadeh ${ }^{2,3}$, Younes Ghasemi ${ }^{2,3}$ (D), Alireza Ebrahiminezhad ${ }^{1,2^{*}}$ (D)
}

1. Department of Medical Biotechnology, School of Advanced Medical Sciences and Technologies, Shiraz University of Medical Sciences, Shiraz, Iran

2. Department of Pharmaceutical Biotechnology, School of Pharmacy, Shiraz University of Medical Sciences, Shiraz, Iran.

3. Pharmaceutical Sciences Research Center, Shiraz University of Medical Sciences, Shiraz, Iran.

\begin{tabular}{|c|c|}
\hline $\begin{array}{l}\text { Use your device to scan } \\
\text { and read the article online }\end{array}$ & \\
\hline 口pht回 & 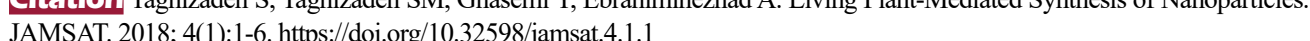 \\
\hline 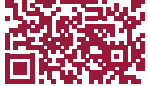 & dol' https://doi.org/10.32598/jamsat.4.1.1 \\
\hline
\end{tabular}

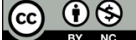

Article info:

Received: 10 Aug 2017

Accepted: 13 Jan 2018

Available Online: 01 Mar 2018

\section{Keywords:}

Biosynthesis, Green synthesis, Phytomining, Plant mediated synthesis

\begin{abstract}
A B S T RACT
Techniques to fabricate nanostructured materials are in constant development. These techniques initiated with physical and chemical approaches and now are developed to biosynthesis and green synthesis techniques. Nowadays, bioactive compounds from microbial cells and plant extracts are hugely tested and employed for the green synthesis of nanoparticles. Similar to microbial cells that can produce intracellular nanostructures, some plants can synthesize and maintain nanostructures in their tissue. The evidence of these finding is the phytomining technology. Now it is known that various parameters such as soil $\mathrm{pH}$, geographical area, and ionic precursor can influence the process of in situ fabrication of nanoparticles. Plant metabolites such as terpenoids, polyphenols, reducing sugars, alkaloids, phenolic acids, and proteins play a major role in the reduction of metal ions as well as stabilization of the produced nanoparticles. These in situ synthesized nanoparticles can be extracted and purified via ashing techniques.
\end{abstract}

\section{Highlights}

- Green plants can synthesize and maintain nanoparticles in their tissues.

- The plants can be used for synthesis of $\mathrm{Au}, \mathrm{Ag}, \mathrm{Cu}, \mathrm{Co}, \mathrm{Zn}$, and $\mathrm{Ni}$ nanoparticles.

\section{Plain Language Summary}

Nanoparticles are particles with extremely small size. Their diameters are about 1000 folds smaller than the diameter of human hair (less than $0.0001 \mathrm{~mm}$ ). These particles are unique due to their novel physicochemical and biological properties. In Iran, nanoparticles have gained increasing applications in various technologies. Over the last decade, researchers attempted to find and develop new techniques for the fabrication of these ultra-small particles. Some of these techniques are energy consuming and in most cases employ organic solvents and toxic chemicals. However, plant-mediated synthesis of nanoparticles is a novel approach for the green synthesis of nanoparticles. Plants are abundant with biochemical compounds which are able to reduce metal ions to the nanoparticles and stabilize them. The current review aimed at discussing this issue in detail.

* Corresponding Author:

Alireza Ebrahiminezhad, PhD.

Address: Department of Medical Biotechnology, School of Advanced Medical Sciences and Technologies, Shiraz University of Medical Sciences, Shiraz, Iran. Tel: +98 (71) 32122722

E-mail:a_ebrahimi@susms.ac.ir 


\section{Introduction}

anotechnology is one of the most recent

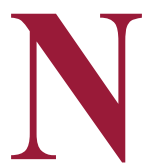
technologies with immense effects on human life. Nanoparticles are now employed in various fields of science and technology. Traditionally, nanoparticles were synthesized via physical and chemical techniques. These techniques are usually performed through harsh processes such as high temperatures and controlled atmosphere. Also, chemical techniques employ toxic materials and organic solvents to do the job [1].

Due to the increasing demand for the nanostructures and nanomaterials, novel approaches are developed to synthetize these compounds. These novel techniques are developed based on the reduction in the application of chemical toxic compounds and organic solvents. Green chemistry emerged as a worldwide trend to make the chemical reactions environmentally friendly and sustainable. Green chemistry is based on the substitution of organic solvents and chemical agents with aqueous matrices and biochemical compounds. Green synthesis and biosynthesis are now familiar terms in the nanostructure fabrication techniques. Now, it is known that biologic materials can be employed to fabricate various nanostructures. Among living creatures, microorganisms and plants are the most employed ones to fabricate nanoparticles in a green manner [2, 3].

Till now, various microbial cells such as bacteria, fungi, diatoms, and microalgae are used to fabricate nanoparticles. The particles can be synthesized extracellularly or intracellularly [2, 4-13]. The major disadvantage of employing microbial cells in the synthesis of nanoparticles is that most of the employed organisms are pathogenic or opportunistic. On the other hand, the media used for the microbial cell cultures are usually complex and expensive. Also, the process of the culture is labor and time consuming. Plants are the next source for cheap and ubiquitous bioactive compounds that can be employed in green synthesis. These bioactive compounds can be simply extracted from the plant into the plant extracts.

Plant extracts are now vastly studied and used for the green synthesis of various nanostructures. The potential of extracts from different parts of plants such as leaf, fruit, flower, and seed is examined for the green synthesis of nanoparticles [3, 14-19]. In addition to plant extract, living plants have also the potential to perform green synthesis of nanoparticles, which means that some living plants are able to synthesize and maintain nanoparticles in their tissue. The current mini review aimed at discuss- ing this issue in details. In this regard, data were provided for the effective parameters that influence formation of nanoparticles in living plants. Also, mechanisms that might be responsible for the living plant mediated synthesis of nanoparticles were presented. Finally, the prospective and limitations of this approach were discussed.

\section{History}

History of the synthesis of nanoparticles in the living plants goes back to the discovery of the phytomining phenomenon. "Phytomining technology" is the employment of hyperaccumulator plants to extract valuable metals that are on a mineralized soil or low-grade ore bodies [20]. Phytomining process studies showed that metals are usually stored as nanoparticles in plants. In situ synthesis of metal nanoparticles comes from metaltolerance ability in plants that helps them to survive in high concentrations of metals by rendering minerals to a nontoxic form (to be farfetched from active metabolic sites of plant) [21, 22].

Gardea-torresdey et al. were among the first groups to evidence the synthesis of gold and silver nanoparticles inside living plants, and opened up a new horizon to fabricate nanoparticles [23, 24]. They used Medicago sativa (alfalfa) on agar medium enriched with AuCl4, and analyzed it through XANES (X-ray absorption near edge structure), EXAFS (extended X-ray absorption fine structure), X-ray, and confirmed the ability of up-taking zero valent gold from solid metal and formation of $\mathrm{Au}$ nanoparticles in different sizes. Further investigations showed the absorption of silver ( $\mathrm{as}^{\mathrm{Ag}} \mathrm{g}^{\mathrm{C}}$ ) and transforming it to the shoot of plant. TEM and STEM analysis approved the arrangement and accumulation of silver atoms inside alfalfa plant to start nucleation and synthesis of Ag nanoparticles. It is interesting that alfalfa can store silver nanoparticles up to $13.6 \%$ of its weight. In addition to gold and silver, synthesis of other noble metal nanoparticles such as $\mathrm{Cu}, \mathrm{Co}, \mathrm{Zn}$, and Ni nanoparticles via exposing living plants to the aqueous metal salt precursors were reported in the following studies reported in the next studies $[25,26]$.

\section{Effective Parameters}

Formation of nanoparticles in living plants is influenced by some environmental parameters [27-29]. Armendariz et al. observed that the size of gold nanoparticles greatly varied by altering $\mathrm{pH}$ value of the medium from biomass of Avena sativa [30]. The source of metals is also a critical factor in biosynthesis of nanoparticles in living plants. For instance, when Brassica junea was 
supplied with $\mathrm{AgNO}_{3}$, the size of biosynthesized silver nanoparticles was around 10-35 nm, whereas plants supplied with $\mathrm{Ag}\left(\mathrm{NH}_{3}\right)^{2+}$ complex, synthesized the nanoparticles of about $2 \mathrm{~nm}$ in size [31].

Authors` recent study showed that geographical area is a significant factor in the process of in situ nanoparticles production. In the current study, the ability of three strains of Iranian alfalfa plants, harvested from different geographical areas, was examined for in situ synthesis of AuNPs. Results indicated that the type of alfalfa plant, concentrations of $\mathrm{HAuCl} 4, \mathrm{pH}$ of the culture media, and duration of exposure to $\mathrm{HAuCl} 4$ were the main factors in the synthesis of AuNPs [32].

\section{Mechanism}

Recent investigations hypothesized that big-reducing sugars and fructose in chloroplasts were responsible to convert metal salts into nanoparticles. Furthermore, plant metabolites such as terpenoids, polyphenols, sugars, alkaloids, phenolic acids, and proteins play a major role in the reduction of metal ions as well as stabilization of the produced nanoparticles. Further analyses confirmed that the synthesis of nanoparticles started some ultrastructural changes in different cell compartments. In response to the presence of high concentrations of nanoparticles, cells change their subcellular organization. One of these important changes occurs in cell membranes. High concentrations of silver nanoparticles can lead to the inhibition of sulfhydryl enzymes in cell membranes (e.g. membrane of plasmalemma, tonoplast, and chloroplast thylakoids), which modify membrane permeability and, as a result, cell damage [33-35].

In general, the synthesis mechanism of metal nanoparticles in a living plant consists of three main steps; the first step is activation phase, in which ions are reduced and the nuclei of the nanoparticles are formed; in the second step, growth phase, small nanoparticles are interconnected to make up larger particles, this phase is accompanied by an increase in the nanoparticles thermodynamic stability; eventually, in the termination phase, the final shape of the nanoparticles is determined, in this phase, nanoparticles have the most stable thermodynamic properties [36].

\section{Prospective}

Although living plants can be used to synthesize metal nanoparticles, this technology has limitations that challenge the entry of produced nanoparticles into the realm of industry. The size and shape of the synthesized nanoparticles are highly dependent on their storage position in the plant, which can be due to the difference in the permeability of metal ions in different parts of the plant and/or the presence of different biomolecules in different parts of the plant [37-40].

The heterogeneity of the size and shape of nanoparticles produced in a living plant that has high sensitivity to the shape and size of nanoparticles are the main drawbacks to their application in industries. Extraction and purification of in situ synthesized nanoparticles is another drawback of in situ synthesis. The metal nanoparticles accumulated in the plant tissue can be extracted by ashing and purification. But, this method has some major disadvantages such as complexity, high cost, and low efficiency. In addition to all these problems, environmental issues are the most controversial and challenging topic in this realm.

\section{Conclusion}

In situ synthesis of nanoparticles is one of the green techniques to fabricate nanoparticles. In contrast to the other green approaches such as using microbial synthesis or plant extract mediated synthesis, this technique does not seems to be efficient enough. But, by developing the phytomining technologies and introducing plants or even recombinant plants with increased efficiency for in situ syntheses of nanoparticles, this technique can be employed as nanoagriculture. It means that in the future it is possible to have farms that produce nanoparticles from the soil.

\section{Ethical Considerations}

\section{Compliance with ethical guidelines}

There was no ethical considerations to be considered in this research.

\section{Funding}

This research was financially supported by Shiraz University of Medical Sciences, Shiraz, Iran.

\section{Authors contributions}

Writing: Saeed Taghizadeh and Seyedeh-Masoumeh Taghizadeh; Resources: Younes Ghasemi; Writing review \& editing: Alireza Ebrahiminezhad.

\section{Conflict of interest}

The authors declared no conflict of interest. 


\section{References}

[1] Mehr FP, Khanjani M, Vatani P. Synthesis of nano-ag particles using sodium borohydride. Oriental Journal of Chemistry. 2015; 31(3):1831-3. [DOI:10.13005/ojc/310367]

[2] Ebrahiminezhad A, Zare M, Kiyanpour S, Berenjian A, Niknezhad SV, Ghasemi Y. Biosynthesis of xanthan gum coated iron nanoparticles by using Xanthomonas campestris. IET Nanobiotechnology. 2017; 12(3):254-8

[3] Ebrahiminezhad A, Zare Hoseinabadi A, Sarmah AK, Taghizadeh S, Ghasemi Y, Berenjian A. Plant-mediated synthesis and applications of Iron nanoparticles. Molecular Biotechnology. 2018; 60(2):154-68. [DOI:10.1007/s12033-0170053-4] [PMID]

[4] Ebrahiminezhad A, Bagheri M, Taghizadeh SM, Berenjian A, Ghasemi Y. Biomimetic synthesis of silver nanoparticles using microalgal secretory carbohydrates as a novel anticancer and antimicrobial. Advances in Natural Sciences: Nanoscience and Nanotechnology. 2016; 7(1):015018.

[5] Kianpour S, Ebrahiminezhad A, Mohkam M, Tamaddon AM, Dehshahri A, Heidari R, et al. Physicochemical and biological characteristics of the nanostructured polysaccharide-iron hydrogel produced by microorganism Klebsiella oxytoca. Journal of Basic Microbiology. 2017; 57(2):132-40. [DOI:10.1002/jobm.201600417]

[6] Kianpour S, Ebrahiminezhad A, Negahdaripour M, Mohkam M, Mohammadi F, Niknezhad S, et al. Characterization of biogenic Fe (III)-binding exopolysaccharide nanoparticles produced by Ralstonia sp SK03. Biotechnology Progress. 2018; 34(5):1167-76. [DOI:10.1002/btpr.2660] [PMID]

[7] Ali DM, Sasikala M, Gunasekaran M, Thajuddin N. Biosynthesis and characterization of silver nanoparticles using marine cyanobacterium, oscillatoria willei NTDM01. Digest Journal of Nanomaterials and Biostructures. 2011; 6(2):385-90

[8] Chokshi K, Pancha I, Ghosh T, Paliwal C, Maurya R, Ghosh $\mathrm{A}$, et al. Green synthesis, characterization and antioxidant potential of silver nanoparticles biosynthesized from deoiled biomass of thermotolerant oleaginous microalgae Acutodesmus dimorphus. RSC Advances. 2016; 6(76):72269-74. [DOI:10.1039/C6RA15322D]

[9] Kannan RRR, Arumugam R, Ramya D, Manivannan K Anantharaman P. Green synthesis of silver nanoparticles using marine macroalga chaetomorpha linum. Applied Nanoscience. 2013; 3(3):229-33. [DOI:10.1007/s13204-012-0125-5]

[10] Kathiraven T, Sundaramanickam A, Shanmugam N, Balasubramanian T. Green synthesis of silver nanoparticles using marine algae Caulerpa racemosa and their antibacterial activity against some human pathogens. Applied Nanoscience. 2015; 5(4):499-504. [DOI:10.1007/s13204-014-0341-2]

[11] Mohseniazar M, Barin M, Zarredar H, Alizadeh S, Shanehbandi D. Potential of microalgae and lactobacilli in biosynthesis of silver nanoparticles. Biolmpacts. 2011; 1(3):149-52. [PMID] [PMCID]

[12] Prasad TN, Kambala VSR, Naidu R. Phyconanotechnology: Synthesis of silver nanoparticles using brown marine algae Cystophora moniliformis and their characterisation. Journal of Applied Phycology. 2013; 25(1):177-82. [DOI:10.1007/ s10811-012-9851-z]
[13] Sinha SN, Paul D, Halder N, Sengupta D, Patra SK. Green synthesis of silver nanoparticles using fresh water green alga Pithophora oedogonia (Mont.) Wittrock and evaluation of their antibacterial activity. Applied Nanoscience. 2015, 5(6):703-9. [DOI:10.1007/s13204-014-0366-6]

[14] Ebrahiminezhad A, Barzegar Y, Ghasemi Y, Berenjian A. Green synthesis and characterization of silver nanoparticles using Alcea rosea flower extract as a new generation of antimicrobials. Chemical Industry \& Chemical Engineering Quarterly. 2017; 23(1):31-7.

[15] Ebrahiminezhad A, Taghizadeh S, Berenjian A, Heidaryan Naeini F, Ghasemi Y. Green synthesis of silver nanoparticles capped with natural carbohydrates using ephedra intermedia. Nanosci Nanotechnol Asia. 2016; 6:1-9.

[16] Ebrahiminezhad A, Taghizadeh S, Berenjiand A, Rahi A, Ghasemi Y. Synthesis and characterization of silver nanoparticles with natural carbohydrate capping using Zataria multiflora. Nanoscience \& Nanotechnology-Asia. 2017; 7(1):104-12 [DOI:10.5185/amlett.2016.6458]

[17] Ebrahiminezhad A, Taghizadeh S, Ghasemi Y. Green synthesis of silver nanoparticles using Mediterranean Cypress (cupressus sempervirens) leaf extract. American Journal of Biochemistry and Biotechnology. 2017; 13(1):1-6. [DOI:10.3844/ ajbbsp.2017.1.6]

[18] Ebrahiminezhad A, Taghizadeh S, Ghasemi Y, Berenjian A. Green synthesized nanoclusters of ultra-small zero valent iron nanoparticles as a novel dye removing material. Science of the Total Environment. 2017; 621:1527-32. [DOI:10.1016/j. scitotenv.2017.10.076]

[19] Ebrahiminezhad A, Zare Hoseinabadi A, Berenjian A, Ghasemi Y. Green synthesis and characterization of zero-valent iron nanoparticles using stinging nettle (Urtica dioica) leaf extract. Green Processing and Synthesis. 2017; 6(5):1-8. [DOI 10.1515/gps-2016-0133]

[20] Marshall AT, Haverkamp RG, Davies CE, Parsons JG, Gardea Torresdey JL, van Agterveld D. Accumulation of gold nanoparticles in Brassic juncea. International Journal of Phytoremediation. 2007; 9(3):197-206. [DOI:10.1080/15226510701376026] [PMID]

[21] Wilson Corral V, Anderson CW, Rodriguez Lopez M. Gold phytomining. A review of the relevance of this technology to mineral extraction in the $21^{\text {st }}$ century. Journal of Environmental Management. 2012; 111:249-57. [DOI:10.1016/j.jenvman.2012.07.037] [PMID]

[22] Sheoran V, Sheoran AS, Poonia P. Phytomining: A review. Minerals Engineering. 2009; 22(12):1007-19. [DOI:10.1016/j mineng.2009.04.001]

[23] Gardea Torresdey J, Parsons J, Gomez E, Peralta Videa J, Troiani H, Santiago P, et al. Formation and growth of au nanoparticles inside live alfalfa plants. Nano Letters. 2002 2(4):397-401. [DOI:10.1021/nl015673]

[24] Gardea Torresdey JL, Gomez E, Peralta Videa JR, Parsons JG, Troiani H, Jose Yacaman M. Alfalfa sprouts: A natural source for the synthesis of silver nanoparticles. Langmuir. 2003; 19(4):1357-61. [DOI:10.1021/la020835i]

[25] Bali R, Razak N, Lumb A, Harris A. The synthesis of metallic nanoparticles inside live plants. Pepar presented at: International Conference on Nanoscience and Nanotechnology. 3-7 July 2006; Brisbane, Australia. [DOI:10.1109/ ICONN.2006.340592] 
[26] Mukundan D, Vasanthakumari R. Phytoengineered nanomaterials and their applications. In: Prasad R, Kumar V, Kumar M, editors. Nanotechnology. Berlin: Springer; 2017.

[27] Weier E. Factors affecting the reduction of silver nitrate by chloroplasts. American Journal of Botany. 1938; 25(7):501-7. [DOI:10.1002/j.1537-2197.1938.tb09251.x]

[28] Starnes DL, Jain A, Sahi SV. In planta engineering of gold nanoparticles of desirable geometries by modulating growth conditions: An environment-friendly approach. Environmental Science \& Technology. 2010; 44(18):7110-5.

[29] Aubert T, Burel A, Esnault MA, Cordier S, Grasset F, Cabello Hurtado F. Root uptake and phytotoxicity of nanosized molybdenum octahedral clusters. Journal of Hazardous Materials. 2012; 219-220:111-8. [DOI:10.1016/j.jhazmat.2012.03.058]

[30] Armendariz V, Herrera I, Jose yacaman M, Troiani H, Santiago P, Gardea Torresdey JL. Size controlled gold nanoparticle formation by Avena sativa biomass: Use of plants in nanobiotechnology. Journal of Nanoparticle Research. 2004; 6(4):377-82. [DOI:10.1007/s11051-004-0741-4]

[31] Shekhawat G, Arya V. Biological synthesis of ag nanoparticles through in vitro cultures of Brassica juncea C zern. Advanced Materials Research. 2009; 67:295-9.

[32] Keshavarzi M, Davoodi D, Pourseyedi S, Taghizadeh S. The effects of three types of alfalfa plants (medicago sativa) on the biosynthesis of gold nanoparticles: An insight into phytomining. Gold Bulletin. 2018; 51(3):1-12. [DOI:10.1007/ s13404-018-0237-0]

[33] Gan PP, Li SF. Potential of plant as a biological factory to synthesize gold and silver nanoparticles and their applications. Reviews in Environmental Science and Bio/Technology. 2012; 11(2):169-206. [DOI:10.1007/s11157-012-9278-7]

[34] Tripathi DK, Singh S, Singh S, Dubey NK, Chauhan DK. Impact of nanoparticles on photosynthesis: Challenges and opportunities. Materials Focus. 2016; 5(5):405-11. [DOI:10.1166/ mat.2016.1327]

[35] Marchiol L, Mattiello A, Pošćić F, Giordano C, Musetti R. In vivo synthesis of nanomaterials in plants: Location of silver nanoparticles and plant metabolism. Nanoscale Research Letters. 2014; 9(1):101. [DOI:10.1186/1556-276X-9-101] [PMID] [PMCID]

[36] Manceau A, Nagy KL, Marcus MA, Lanson M, Geoffroy N, Jacquet $\mathrm{T}$, et al. Formation of metallic copper nanoparticles at the soil-root interface. Environmental Science \& Technology. 2008; 42(5):1766-72.

[37] Corredor E, Testillano PS, Coronado MJ, González Melendi $P$, Fernández Pacheco R, Marquina $C$, et al. Nanoparticle penetration and transport in living pumpkin plants: In situ subcellular identification. BMC Plant Biology. 2009; 9:45. [DOI:10.1186/1471-2229-9-45]

[38] Koontz HV, Berle KL. Silver uptake, distribution, and effect on calcium, phosphorus, and sulfur uptake. Plant Physiology. 1980; 65(2):336-9. [DOI:10.1104/pp.65.2.336] [PMID] [PMCID]

[39] Haverkamp RG, Marshall AT, van Agterveld D. Pick your carats: Nanoparticles of gold-silver-copper alloy produced in vivo. Journal of Nanoparticle Research. 2007; 9(4):697-700.
[40] Harris AT, Bali R. On the formation and extent of uptake of silver nanoparticles by live plants. Journal of Nanoparticle Research. 2008; 10(4):691-5. 
This Page Intentionally Left Blank 